\title{
Types of coeliac trunk branching including accessory hepatic arteries: a new point of view based on cadaveric study
}

\author{
Ł. Olewnik ${ }^{1}$, G. Wysiadecki ${ }^{1}$, M. Polguj ${ }^{2}$, A. Waśniewska ${ }^{1}$, M. Jankowski ${ }^{1}$, M. Topol ${ }^{1}$ \\ ${ }^{1}$ Department of Normal and Clinical Anatomy, Interfaculty Chair of Anatomy and Histology, Medical University of Lodz, Poland \\ 2Department of Angiology, Interfaculty Chair of Anatomy and Histology, Medical University of Lodz, Poland
}

[Received: 10 December 2016; Accepted: 11 April 2017]

\begin{abstract}
Background: The coeliac trunk (CT) is major visceral branch of the abdominal aorta. Familiarity with anatomic variations of the CT is relevant for planning radiological and surgical procedures. The aim of our research was determining variations of the CT, including the occurrence of accessory hepatic arteries (AHA). Materials and methods: Forty cadavers were studied. Six patterns of CT branching were observed in this study. AHA were observed in 7 (17.5\%) specimens. The most prevalent variation was normal trifurcation, accounting for $62.5 \%$ of cases. The rarest variation was absence of the CT, with an incidence of $2.5 \%$. In this variant the left gastric artery, the common hepatic artery, and the splenic artery branched directly off the abdominal aorta.

Results: The study material allowed to distinguish two CT branching patterns which, to the best of our knowledge, have not been reported before. It was a type with four branches originating from the CT: the left gastric artery, the common hepatic artery, the splenic artery, and right AHA. The other previously unreported pattern variant was the CT which gave off three branches: the common hepatic artery, the splenic artery and right AHA.

Conclusions: The average distance between the aortic hiatus and the coeliac trunk calculated for all the cadavers amounted to $54 \pm 11.85 \mathrm{~mm}$. The average distance between the CT and the superior mesenteric artery was $11.1 \pm 7.7 \mathrm{~mm}$. (Folia Morphol 2017; 76, 4: 660-667)
\end{abstract}

Key words: anatomical variations, accessory hepatic artery, coeliac trunk, hepatosplenic trunk, left gastric artery

\section{INTRODUCTION}

In antiguity Galen was the first to describe the distribution of coeliac trunk (CT) branches, as he concluded during his research that blood supplying the stomach, liver and spleen comes from another source than blood supplying the intestines [13]. In the $16^{\text {th }}$ century, Andreas Vesalius found out that the $\mathrm{CT}$ is divided into two branches: left and right. The right branch is the hepatic artery, while the left is the splenic artery, where the stomach arteries originate, including the left gastric artery (LGA) [13]. Jacques Benigne Winslow and Albert von Haller were the first to describe the normal anatomy of the CT. Winslow also described CT branches, while von Haller reported on variations in hepatic arteries [13].

The $\mathrm{CT}$ is a major single visceral branch of the abdominal aorta; it is a thick and short artery whose 
length ranges from $15 \mathrm{~mm}$ to $20 \mathrm{~mm}$. The most common branches of the CT are: the splenic artery, the common hepatic artery and the LGA $[4,17]$. Nonetheless, the $\mathrm{CT}$ shows considerable anatomic variations $[1-5,7,11-17]$. There have been reports of double, triple and even quadruple branches originating in the CT $[4,5,12]$.

Familiarity with anatomic variations of the $\mathrm{CT}$ is relevant for planning radiological and surgical procedures in the abdominal part of the oesophagus, stomach, duodenum, liver, pancreas, gallbladder, and spleen $[5,9,12,17,18]$. Modern transplantology requires knowledge on vascular variations, including incidence of accessory hepatic arteries (AHA) $[10,15]$. Araujo Neto et al. [2] also suggested that the coeliac trunk's diameter, as well as the distance between the trunk and the superior mesenteric artery should be estimated prior to a surgical procedures. Moreover, in every case, distribution of an AHA may vary and be essential from the functional point of view $[9,10]$.

The aim of our research is determining variations of branches origin from the $\mathrm{CT}$ and its anatomic variations, including the occurrence of AHA in the Polish population, which may be relevant for minimising complications after diagnostic tests and surgical procedures.

A novelty in this work is classification of two new types of CT branches including AHA, which is associated with more frequent selective endovascular application of chemioterapeutics to tumours of the liver (most often metastasis or hepatocellular carcinoma) or selective embolisation.

\section{MATERIALS AND METHODS}

Fourty cadavers, including 22 male (M) and 18 female (F) cadavers, were studied. The cadavers were fixed in a $10 \%$ formalin solution. The specimens had no traces of surgical intervention in the abdominal area. The Local Bioethics Commission issued a consent for the study (consent no. RNN/93/16/KE).

The study was carried out with classical dissection techniques. During the dissection, the CT morphology, the point where it branched off the abdominal aorta in reference to the spine, and presence of AHA were evaluated. The next stage consisted in morphometric measurements of the distance between the $\mathrm{CT}$ and the superior mesenteric artery, between the $\mathrm{CT}$ and the aortic hiatus of the diaphragm, and between the trunk and the abdominal aorta bifurcation. The measurements were taken with an electronic calliper (Mitutoyo Corporation, Kawasaki-shi, Kanagawa, Japan). Each measurement was taken independently twice by two people with high experience in anatomical dissection and was accurate within $0.1 \mathrm{~mm}$. Basic descriptive statistics were calculated with Excel for the collected data.

\section{RESULTS}

The study revealed different variations of the CT and variable points of its branching off the abdominal aorta. Six patterns of CT branching were observed in the course of this study:

- Typical trifurcation variation - a typical branching pattern of the $\mathrm{CT}$, with the LGA, the common hepatic artery and the splenic artery branching off the trunk (Fig. 1). This pattern was found in 25 cases (14 M, 11 F/62.5\%);

- Four-branch trunk variation - CT + right AHA. Apart from the three typical branches, there was an AHA branching off the trunk (Fig. 2). This pattern was observed in 3 cases (2 M/1 F/7.5\%);

- Coeliacophrenic trunk variation - the CT gave off four branches: the LGA, the common hepatic artery, the splenic artery, and additionally the left inferior phrenic artery (Fig. 3). This pattern was observed in 5 cases ( $3 \mathrm{M}, 2 \mathrm{~F} / 12.5 \%)$;

- Bifurcation - hepatosplenic trunk - two main branches originated in the CT: the common hepatic artery and the splenic artery (Fig. 4). This type of variation was observed in 4 cases (1 M/3 F/10\%);

- Trifurcation - hepatosplenic trunk + right AHA - the CT gave off three branches: the common hepatic artery, the splenic artery and right AHA. The LGA branched directly off the abdominal aorta and gave off a phrenic branch (Fig. 5). This variation was found in 2 cases ( $2 \mathrm{M} / 5 \%$ );

- Absence of the CT - the LGA, the common hepatic artery, and the splenic artery branched directly off the abdominal aorta (Fig. 6). This pattern was found in 1 case $(1 \mathrm{~F} / 2.5 \%)$.

The level at which the CT branched off the abdominal aorta in relation to the spine was also evaluated. In 14 cases the CT originated at the level of the $12^{\text {th }}$ thoracic vertebra (35\%), in $8(20 \%)$ cases between the $12^{\text {th }}$ thoracic and the first lumbar vertebra, and in 18 specimens it originated at the level of the first lumbar vertebra (45\%). 


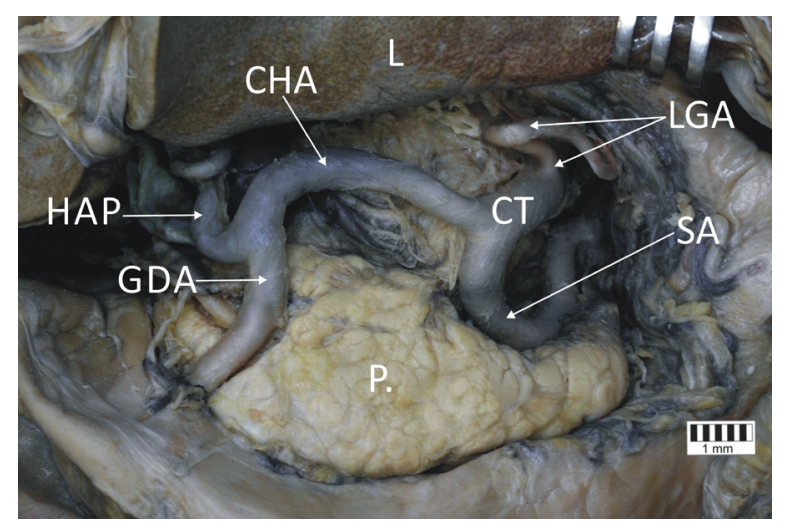

Figure 1. Typical trifurcation trunk; CT — coeliac trunk; SA splenic artery; CHA — common hepatic artery; LGA — left gastric artery; HAP — hepatic artery proper; GDA — gastroduodenal artery; L — liver; $\mathrm{P}$ - pancreas.

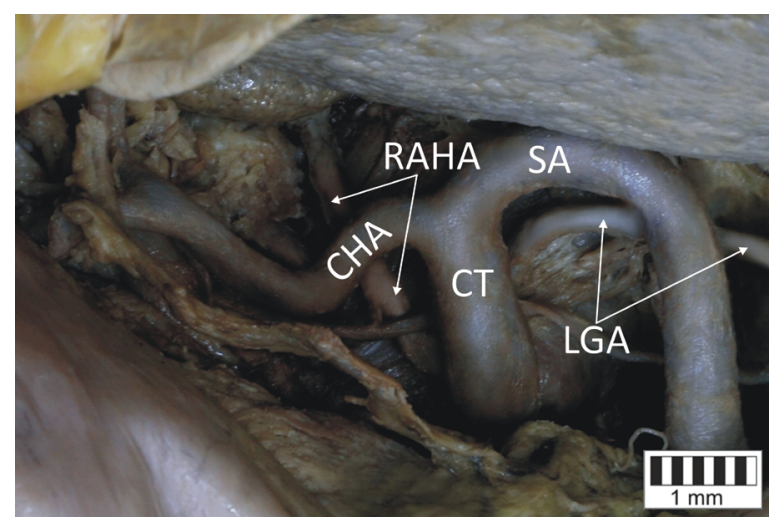

Figure 2. Four-branch trunk; CT — coeliac trunk; $S A$ - splenic artery; CHA — common hepatic artery; LGA — left gastric artery; RAHA — right accessory hepatic artery.

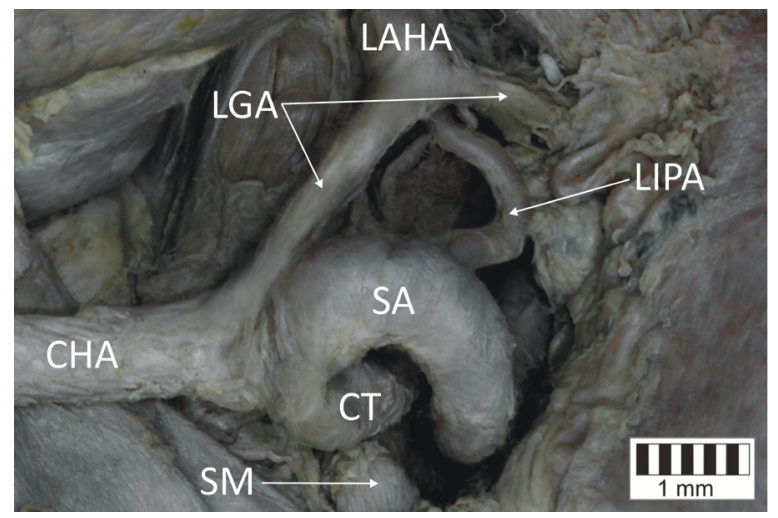

Figure 3. Coeliacophrenic trunk; CT — coeliac trunk; SA — splenic artery; CHA — common hepatic artery; LGA — left gastric artery; LAHA — left accessory hepatic artery; LIPA — left inferior phrenic artery; SM — superior mesenteric artery

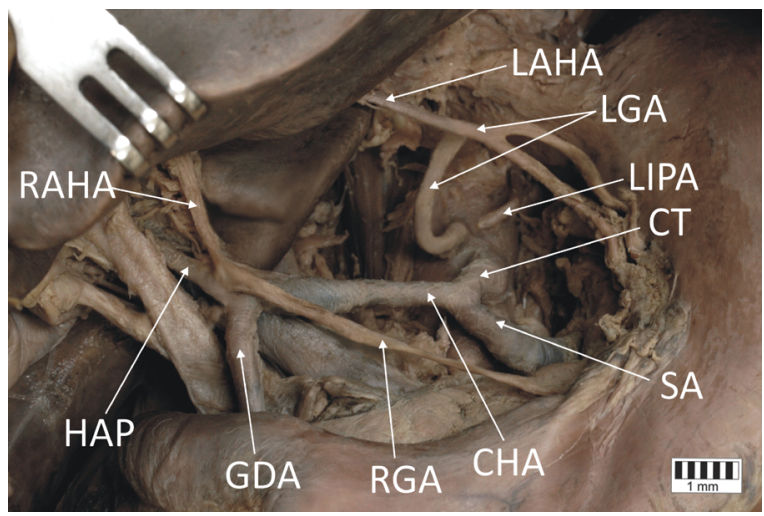

Figure 4. Hepatosplenic trunk; $C T$ - coeliac trunk; $S A-$ splenic artery; CHA — common hepatic artery; LGA — left gastric artery; LAHA — left accessory hepatic artery; RAHA — right accessory hepatic artery; LIPA — left inferior phrenic artery; RGA — right gastric artery; GDA — gastroduodenal artery; HAP — hepatic artery proper.

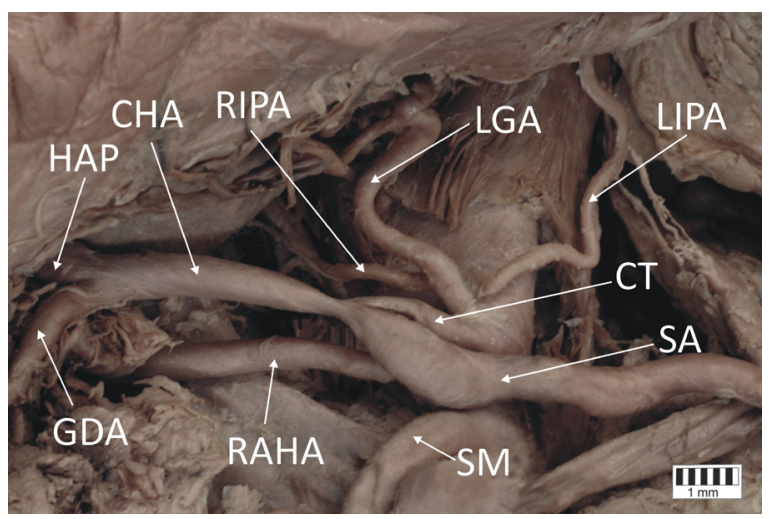

Figure 5. Hepatosplenic trunk and right accessory hepatic artery (RAHA); CT — coeliac trunk; SA — splenic artery; CHA — common hepatic artery; LGA — left gastric artery; HAP — hepatic artery proper; GDA — gastroduodenal artery; LIPA — left inferior phrenic artery; RIPA — right inferior phrenic artery; LAHA — left accessory hepatic artery; SM — superior mesenteric artery.

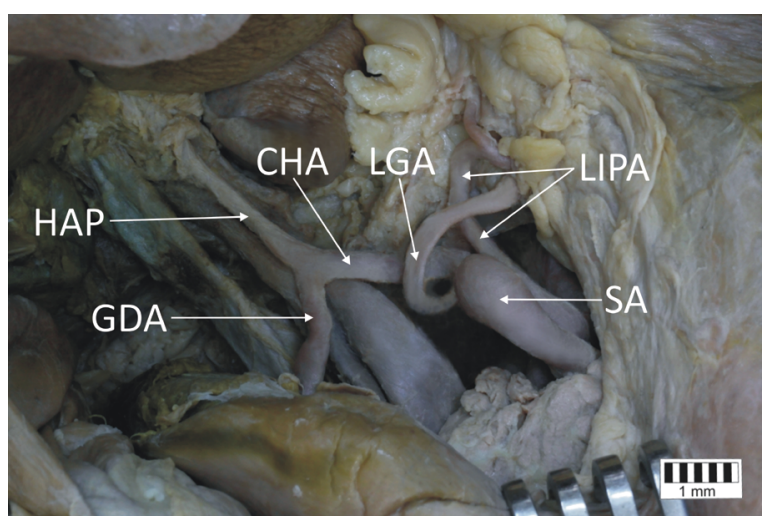

Figure 6. Absence of the coeliac trunk; SA — splenic artery; CHA common hepatic artery; LGA — left gastric artery; LIPA — left inferior phrenic artery; GDA - gastroduodenal artery; HAP — hepatic artery proper. 


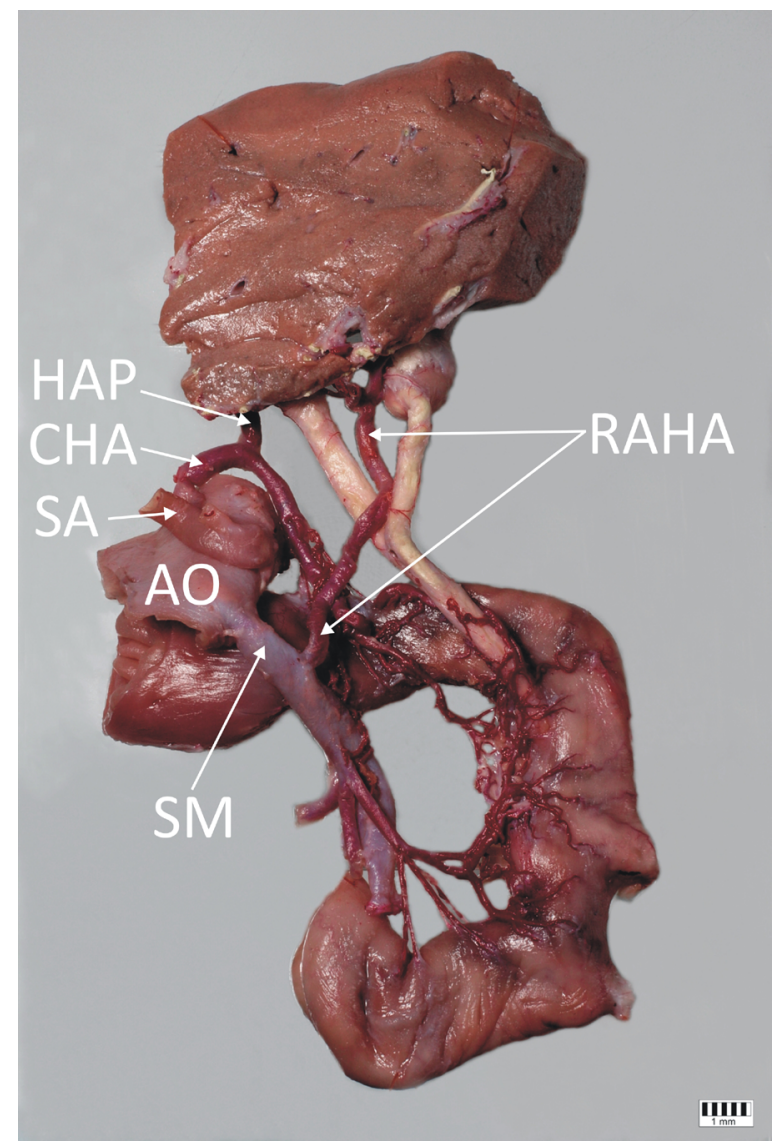

Figure 7. Right accessory hepatic artery (RAHA) originating from the superior mesenteric artery (SM); $\mathrm{AO}$ - abdominal aorta; $\mathrm{SA}$ splenic artery; CHA — common hepatic artery; HAP — hepatic artery proper.

The study material revealed presence of AHA. On the whole, in 7 cadavers 9 AHA were found. In 1 case, left AHA branched off the LGA, which in turn branched directly off the abdominal aorta (Fig. 4). In another case, right AHA branched off the proper hepatic artery (Fig. 4). Co-occurrence of 2 AHA was observed in 1 case, more precisely, one of the left AHA branched off the LGA (it was a direct branch of the abdominal aorta), while the other right AHA branched off the proper hepatic artery (Fig. 4). There was also a case in which left AHA branched off the LGA, and it in turn branched off the CT (Fig. 3). There was also a case found of right $\mathrm{AHA}$ originating from the superior mesenteric artery (Fig. 7). In 5 cadavers, an AHA branched directly off the CT (Figs. 2 and 5).

The average distance between the aortic hiatus and the CT calculated for all the cadavers amounted to $54 \mathrm{~mm}(25.4-83.4 \mathrm{~mm}, \mathrm{SD}=11.85 \mathrm{~mm}$, median $=51.3 \mathrm{~mm})($ Table 1$)$. The average distance between the CT and the superior mesenteric artery was $11.1 \mathrm{~mm}(1.5-25.9 \mathrm{~mm}, \mathrm{SD}=7.7$, median $=$ $8.6 \mathrm{~mm}$ ) (Table 2). The average distance between the CT and the inferior mesenteric artery was $84.2 \mathrm{~mm}$ $(55-112.8 \mathrm{~mm}, \mathrm{SD}=14.7 \mathrm{~mm}$, median $=83.4 \mathrm{~mm})$ (Table 3). The average distance between the CT and the abdominal aorta bifurcation amounted to $132 \mathrm{~mm}$ (96-165.2 mm, SD = $16.4 \mathrm{~mm}$, median $=131.4 \mathrm{~mm}$ ), both the lowest and the highest value was found in a male (Table 4). In females, the average distance was $129.7 \mathrm{~mm}$ (105.7-160.5 mm), whereas in males it was $133.7 \mathrm{~mm}$ (96-165.2 mm) (Table 4).

\section{DISCUSSION}

So far, there have been various classifications of the $\mathrm{CT}$ devised based on its anatomical branching pattern. The first classification was formulated by Lipshutz in 1917 [7], and it covered four branching types (Table 5). In 1928, Adachi and Hasabe [1] created a classification including six types of the CT (Table 5). Other researchers who proposed classifications of the CT were: Araujo Neto et al. [2], Selvaraj and Sundaramurthi [14], Prakash et al. [12], Wadhwa and Sonia [19], as well as Song et al. [16] (Table 6).

The most prevalent variation in our study was normal trifurcation, accounting for $62.5 \%$ of cases. Lipshutz [7] observed this variant in $75 \%$ of cases, and Adachi and Hasabe [1] in $86 \%$ of cases. Araujo Neto et al. [2] found this variation in 54 (90\%) patients, while Selvaraj and Sundaramurthi [14] in 68 out of $75(90.6 \%)$ patients. Also in the studies conducted by Prakash et al. [12] and by Wadhwa and Sonia [19] this type emerged as the most common - with incidence of $86 \%$ and $93.3 \%$, respectively $[12,19]$. Song et al. [16] studied 5002 patients and found normal trifurcation in 4457 cases (89.1\%).

The second most common branching type was coeliacophrenic trunk (12.5\%). This type of branching pattern was also included in Pushpalatha's classification and it accounted for $14 \%$ of cases [11].

The thirth most common pattern was hepatosplenic trunk. In our material it accounted for $10 \%$ of cases. This coeliac trunk branching pattern was the second most common variation in Lipshutz's and Adachi's studies, with incidence of 15\% [7] and 8\% [1], respectively. In the research done by Araujo Neto et al. [2], Prakash et al. [12], Selvaraj and Sundaramurthi [14], Wadhwa and Sonia [19], as well as Song et al. [16] it was also revealed to be the second most prevalent variation (Table 6). Wadhwa and Sonia [19] 
Table 1. The distance between the coeliac trunk and the aortic hiatus

\begin{tabular}{lccccc}
\hline Group & $\begin{array}{c}\text { The minimum } \\
\text { distance }\end{array}$ & $\begin{array}{c}\text { The maximum } \\
\text { distance }\end{array}$ & $\begin{array}{c}\text { The average } \\
\text { distance }\end{array}$ & Median & $\begin{array}{c}\text { Standard } \\
\text { deviation }\end{array}$ \\
\hline All & 25.44 & 83.36 & 54.04 & 51.30 & 11.85 \\
Women & 45.53 & 83.36 & 58.31 & 53.83 & 12.24 \\
Men & 35.17 & 78.50 & 50.62 & 49.43 & 10.68 \\
\hline
\end{tabular}

Table 2. The distance between coeliac trunk and the superior mesenteric artery

\begin{tabular}{lccccc}
\hline Group & $\begin{array}{c}\text { The minimum } \\
\text { distance }\end{array}$ & $\begin{array}{c}\text { The maximum } \\
\text { distance }\end{array}$ & $\begin{array}{c}\text { The average } \\
\text { distance }\end{array}$ & Median & $\begin{array}{c}\text { Standard } \\
\text { deviation }\end{array}$ \\
\hline All & 1.54 & 25.92 & 11.07 & 8.59 & 7.72 \\
Women & 2.39 & 24 & 10.88 & 8.15 & 8.13 \\
Men & 3.09 & 25.92 & 11.22 & 10.46 & 7.62 \\
\hline
\end{tabular}

Table 3. The distance between the coeliac trunk and the inferior mesenteric artery

\begin{tabular}{lccccc}
\hline Group & $\begin{array}{c}\text { The minimum } \\
\text { distance }\end{array}$ & $\begin{array}{c}\text { The maximum } \\
\text { distance }\end{array}$ & $\begin{array}{c}\text { The average } \\
\text { distance }\end{array}$ & Median & $\begin{array}{c}\text { Standard } \\
\text { deviation }\end{array}$ \\
\hline All & 55 & 112.85 & 84.22 & 83.40 & 14.74 \\
Women & 59.47 & 102.33 & 81.89 & 82.88 & 13.05 \\
Men & 55 & 112.85 & 86.02 & 90.63 & 16.06 \\
\hline
\end{tabular}

Table 4. The distance between the coeliac trunk and the aortic bifurcation

\begin{tabular}{lccccc}
\hline Group & $\begin{array}{c}\text { The minimum } \\
\text { distance }\end{array}$ & $\begin{array}{c}\text { The maximum } \\
\text { distance }\end{array}$ & $\begin{array}{c}\text { The average } \\
\text { distance }\end{array}$ & Median & $\begin{array}{c}\text { Standard } \\
\text { deviation }\end{array}$ \\
\hline All & 96 & 165.21 & 131.98 & 131.37 & 16.40 \\
Women & 105.66 & 160.49 & 129.69 & 131.37 & 15.91 \\
Men & 96 & 165.21 & 133.77 & 135.05 & 17.00 \\
\hline
\end{tabular}

Table 5. Comparison of selected classifications of the coeliac trunk

\begin{tabular}{|c|c|c|c|}
\hline Type of coeliac trunk & Lipshutz's [\%] & Adachi's [\%] & Our [\%] \\
\hline Normal trifurcation & 75.0 & 86.0 & 62.5 \\
\hline Hepatosplenic trunk & 15,0 & 8.0 & 10 \\
\hline Hepatogastric trunk & 6.0 & 0.0 & 0 \\
\hline Gastrosplenic trunk & 4,0 & 3.0 & 0 \\
\hline Hepatosplenomesenteric & 0 & 1.0 & 0 \\
\hline Coeliacomesenteric & 0 & 1.5 & 0 \\
\hline Hepatomesenteric trunk & 0 & 0.5 & 0 \\
\hline Quadrifurcation - normal trifurcation + accessory hepatic artery & 0 & 0 & 7.5 \\
\hline Coeliacophrenic trunk - normal trifurcation + left inferior phrenic artery & 0 & 0 & 12.5 \\
\hline Trifurcation - hepatosplenic artery + accessory hepatic artery & 0 & 0 & 5 \\
\hline No coeliac trunk & 0 & 0 & 2.5 \\
\hline
\end{tabular}


Table 6. Comparison of selected classifications of the coeliac trunk

\begin{tabular}{lcccccc}
\hline Type of coeliac trunk & $\begin{array}{c}\text { Song et al. } \\
{[\%]}\end{array}$ & $\begin{array}{c}\text { Neto et al. } \\
{[\%]}\end{array}$ & $\begin{array}{c}\text { Selvaraj et al. } \\
{[\%]}\end{array}$ & $\begin{array}{c}\text { Prakash et al. } \\
{[\%]}\end{array}$ & $\begin{array}{c}\text { Wadhwa } \\
\text { and Sonia } \\
{[\%]}\end{array}$ & $\begin{array}{c}\text { Ours } \\
{[\%]}\end{array}$ \\
\hline Normal trifurcation & 89.1 & 90.0 & 90.6 & 86,0 & 93.3 & 62.5 \\
Hepatosplenic trunk & 4.4 & 8.3 & 8.0 & 4.8 & 6.7 & 10 \\
Hepatogastric trunk & 0.2 & 1.7 & 0 & 1.2 & 0 & 0 \\
Gastrosplenic trunk & 0.2 & 0 & 1.3 & 0 & 0 & 0 \\
Coeliacomesenteric trunk & 1.1 & 0 & 0 & 0 & 0 & 0 \\
Hepatomesenteric trunk & 2.9 & 0 & 0 & 0 & 0 & 0 \\
Splenomesenteric trunk & 3.0 & 0 & 0 & 0 & 0 & 0 \\
Hepatosplenomesenteric trunk & 0.7 & 0 & 0 & 0 & 0 & 0 \\
Gastrosplenomesenteric trunk & 0.2 & 0 & 0 & 0 & 0 & 0 \\
Quadrifurcation-CT + AHA & 0 & 0 & 0 & 0 & 0 & 7.5 \\
Coeliacophrenic trunk-CT + LIPA & 0 & 0 & 0 & 0 & 0 & 12.5 \\
Trifurcation-HT + AHA & 0 & 0 & 0 & 0 & 0 & 5 \\
No coeliac trunk & 0 & 0 & 0 & 4.0 & 0 & 2.5 \\
\hline
\end{tabular}

AHA — accessory hepatic artery; CT — coeliac trunk; HT — hepatosplenic trunk; LIPA — left inferior phrenic artery

studied 30 cadavers and found only two variations of CT branching pattern, namely normal trifurcation and hepatosplenic trunk.

The fourth variation we observed was the $\mathrm{CT}+$ right AHA. We found this type in $7.5 \%$ of cases. This branching pattern has not been previously classified by other authors.

The fifth variation was hepatosplenic trunk + right AHA found in $5 \%$ of cadavers. This pattern has not been described by other authors before.

The dissection revealed a lack of the CT in 1 female cadaver, which is $2.5 \%$ of the study material. Prakash et al. [12] observed a lack of the trunk in 2 specimens, and the LGA, the common hepatic artery, and the splenic artery branched directly off the abdominal aorta. This pattern was also described by Pushpalatha [11] and it was observed in $4 \%$ of cases.

Lipshutz [7] additionally distinguished the hepatogastric trunk variation (6\%). In this pattern, the CT gave off the LGA and the common hepatic artery, while the splenic artery branched directly off the abdominal aorta [7]. This pattern was not observed in Adachi's research [1]. Araujo Neto et al. [2] found it in only $1(1.7 \%$ ) patient (Table 6$)$. The same pattern was observed by Prakash et al. [12] in 1.2\% (Table 6). According to Song et al. [16], this pattern accounted for $0.2 \%$ of cases (Table 6 ). In our study, as well as in the study conducted by Selvaraj and Sundaramurthi [14], this pattern was not found (Tables 5, 6).
In his research, Lipshutz [7] found the gastrosplenic trunk variation in $4 \%$ of his specimens (Table 5 ). In this pattern, both the LGA and the splenic artery originated from the CT. Adachi [1] also described this pattern and reported a 3\% incidence for it (Table 5). Selvaraj and Sundaramurthi [14] found this pattern in only $1(1.3 \%)$ case. The gastroplenic trunk's incidence was $0.2 \%$, according to the study by Song et al. [16]. This pattern was not revealed in our material.

Adachi [1] additionally described three other CT branching patterns (Table 5). The coeliacomesenteric trunk variation consisted in a common branching of the $\mathrm{CT}$ and the superior mesenteric artery, and the reported incidence was $1.5 \%$ [1]. The same pattern was described by Song et al. [16], found in $1.1 \%$ of cases (Table 6). Such a CT type was not encountered in our study.

Adachi [1] also included hepatosplenomesenteric trunk in his classification. In this pattern, the common hepatic artery, the splenic artery, and the superior mesenteric artery had a common branching and this type's incidence was $1 \%$ [1]. The same pattern was observed by Song et al. [16] in $0.7 \%$ of cases. Our classification does not include it.

The last pattern reported by Adachi [1] was hepatomesenteric trunk, which consisted in a branching of the common hepatic artery and the superior mesenteric artery, and was found in $0.5 \%$ of specimens. Song et al. [16] reported finding this type of CT in 
$2.9 \%$ of patients. In our study, this branching pattern did not appear.

Song et al. [16] additionally classified splenomesenteric trunk, with a $3 \%$ incidence. In this pattern, the splenic artery and the superior mesenteric artery had a common branching. The last type reported by Song et al. [16] was gastrosplenomesenteric trunk, where the LGA, the splenic artery and the superior mesenteric artery had a common origin. It was observed in $0.2 \%$ of cases.

Babu and Khrab [3] proposed their own classification of the $\mathrm{CT}$ with multiple variations: 1 . Normal trifurcation; 2. Hepatosplenic trunk; 3. Hepatogastric trunk; 4. Gastrosplenic trunk; 5. No coeliac trunk; 6. Coeliacomesenteric trunk; 7. Hepatomesenteric trunk; 8. Gastromesenteric trunk; 9. Splenomesenteric trunk; 10. Hepatosplenomesenteric trunk; 11. Gastrosplenomesenteric trunk; 12 . Coeliac-colic trunk; 13. Coeliophrenic trunk $(C T+C I P A) ; 14$. Coeliophrenic trunk (CT + RIPA), 15. Coeliophrenic trunk (CT + LIPA). In our research, we found some of the $\mathrm{CT}$ variations classified by these authors, namely: normal trifurcation, hepatosplenic trunk, and coeliophrenic trunk.

Singh et al. [15] measured the distance between the $\mathrm{CT}$ and the superior mesenteric artery, with regard to sex. The average distance between the arteries for both sexes was $8.1 \mathrm{~mm}$. In males, the average distance was $8.1 \mathrm{~mm}$, with the lowest value being $3 \mathrm{~mm}$, and the highest $18 \mathrm{~mm}$. In females, the average distance was $8 \mathrm{~mm}$, with the lowest value at $3 \mathrm{~mm}$, and the highest at $15 \mathrm{~mm}$. The same morphometric measurements were taken by Araujo Neto et al. [2]; however, their research took no account of the sex. The average distance was $1.2 \mathrm{~mm}(0.3-2.3 \mathrm{~mm})$.

According to our research, the average distance between the $\mathrm{CT}$ and the superior mesenteric artery was $11.1 \mathrm{~mm}(1.5-25.9 \mathrm{~mm})$; in females in was $10.9 \mathrm{~mm}$ (2.4-24mm), whileinmalesitwas $11.2 \mathrm{~mm}(3.1-25.9 \mathrm{~mm})$ (Table 2). Additionally, we measured the distance between the CT and the inferior mesenteric artery (Table 3), as well as between the $\mathrm{CT}$ and the abdominal aorta bifurcation (Table 5). We also verified the level at which the $\mathrm{CT}$ branched off the abdominal aorta. Similar research was done by Selvaraj et al. [14]. In their study of 75 patients, they found three levels where the CT originated from the abdominal aorta [14]. In Selvaraj's et al. [14] study, in 8 patients, the CT originated at the level of the $12^{\text {th }}$ thoracic vertebra $(10.7 \%)$, while we observed this level of origin in $14(35 \%)$ cases. According to Selvaraj et al. [14], in 14 patients the CT branched off at the level of the first lumbar vertebra $(18.6 \%)$, and we found 18 cases in which it originated at this level (45\%). In 53 specimens, Selvaraj et al. [14] observed an origin at the level of the intervertebral disc between the $12^{\text {th }}$ thoracic and the first lumbar vertebra $(70.7 \%)$, while our study revealed $8(20 \%)$ such cases. According to the research by Selvaraj et al. [14], the prevalent pattern was a $\mathrm{CT}$ origin at the level of the intervertebral disc between Th12/L1 $-70.7 \%$, whereas in our study the most common origin was found at the level of $\mathrm{L} 1-45 \%$.

During our study, we observed AHA. There were 5 cases of an accessory right hepatic artery originating from the $\mathrm{CT}$; in 3 of those cases, this happened when the CT had standard branches, such as the LGA, the common hepatic artery, and the splenic artery. In 2 of the cases, the CT fell under the 'hepatosplenic category'. To the best of our knowledge, this pattern has never been reported before.

A precise classification of the hepatic arteries was formulated by Hiatt et al. [6] and Michels [8]. In Michels' research, the type of accessory left hepatic artery originating from the LGA was called type V [8], the same pattern was referred to as type II in the study by Hiatt et al. [6]. Ugurel et al. [18] reported this type in ten patients. During our research, we encountered it twice. An accessory right hepatic artery originating from the superior mesenteric artery is in Michels' classification type VI, and in Hiatt's classification type III. Ugurel et al. [18] found it in 1 patient, and we observed it in 1 specimen. Accessory left hepatic artery originating from the LGA and accessory right hepatic artery originating from the superior mesenteric artery in Michels' classification - type VII, and in Hiatt's classifaction - type IV, was found by Ugurel et al. [18] also in 1 patient. We did not observe it in our specimens. However, we found in our study material an origin of an accessory left hepatic artery in the LGA and an origin of the right hepatic artery in the proper hepatic artery.

\section{CONCLUSIONS}

Despite of previous classifications of the $\mathrm{CT}$, the new additional subdivision is needed because we found two types of $\mathrm{CT}$, which have not been included in previous classifications before. It is a type with four branches originating from the CT: (the LGA, the common hepatic artery, the splenic artery, and right AHA). The other previously unreported variant is also a CT which gave off a hepatosplenic trunk and right AHA. 


\section{Acknowledgements}

The authors wish to express their gratitude to all those who donated their bodies to medical science.

\section{REFERENCES}

1. Adachi B, Hasebe K. Das Arteriensystem der Japaner, Anatomie der Japaner. Kaiserlich-japanische Universität zu Kyoto. In kommission bei Maruzen Co., Kyoto and Tokyo 1928.

2. Araujo Neto SA, Franca HA, de Mello Júnior $C F$, et al. Anatomical variations of the celiac trunk and hepatic arterial system: an analysis using multidetector computed tomography angiography. Radiol Bras. 2015; 48(6): 358-362, doi: 10.1590/0100-3984.2014.0100, indexed in Pubmed:26811552.

3. Babu ED, Khrab P. Coeliac trunk variations: review with proposed new classification. Int J Anat Res. 2013; 1(3): 165-170.

4. Bergman RA, Afifi AK, Miyauchi R. llustrated encyclopaedia of human anatomic variation.http://www.anatomyatlases.org/ AnatomicVariants/AnatomyHP.shtml (accessed Feb 2017).

5. Chen H, Yano R, Emura S, et al. Anatomic variation of the celiac trunk with special reference to hepatic artery patterns. Ann Anat. 2009; 191(4): 399-407, doi: 10.1016/j. aanat.2009.05.002, indexed in Pubmed: 19540742.

6. Hiatt JR, Gabbay J, Busuttil RW. Surgical anatomy of the hepatic arteries in 1000 cases. Ann Surg. 1994; 220(1): 50-52, doi: 10.1097/00000658-199407000-00008, indexed in Pubmed: 8024358.

7. Lipshutz B. A composite study of the coeliac axis artery. Ann Surg. 1917; 65(2): 159-169, indexed in Pubmed: 17863663.

8. Michels NA. Newer anatomy of the liver and its variant blood supply and collateral circulation. Am J Surg. 1966; 112(3): 337-347, indexed in Pubmed:5917302.

9. Olewnik $Ł$, Wysiadecki G, Polguj M, et al. A rare anastomosis between the common hepatic artery and the superior mesenteric artery: a case report. Surg Radiol Anat. 2017 [Epub ahead of print], doi: 10.1007/s00276-017-1859-2, indexed in Pubmed: 28432408.

10. Polguj M, Gabryniak T, Topol M. The right accessory hepatic artery; a case report and review of the literature. Surg
Radiol Anat. 2010; 32(2): 175-179, doi: 10.1007/s00276009-0536-5, indexed in Pubmed: 19669076.

11. Pushpalatha K. Study of origin, lengh, diameter and branches of the coeliac trunk and its surgiacal significance. Thesis, Rajiv Gandhi University of Health Sciences, Karnataka, Bangalore 2006. http://14.139.159.4:8080/ jspui/bitstream/123456789/4316/1/CDMANT00018. pdf (accessed Feb 2017).

12. Prakash, Rajini T, Mokhasi V, Geethanjali BS, et al. Coeliac trunk and its branches: anatomical variations and clinical implications. Singapore Med J. 2012; 53(5): 329-331, indexed in Pubmed: 22584973.

13. Sebben GA, Rocha SL, Sebben MA, et al. Variations of hepatic artery: anatomical study on cadavers. Rev Col Bras Cir. 2013; 40(3): 221-226, indexed in Pubmed: 23912370.

14. Selvaraj L, Sundaramurthi I. Study of Normal Branching Pattern of the Coeliac Trunk and its Variations Using CT Angiography. J Clin Diagn Res. 2015; 9(9): AC01AC04, doi: 10.7860/JCDR/2015/12593.6523, indexed in Pubmed: 26500893.

15. Singh BGP, Bhatt CR, Patel SV, et al. Morphometric study of coeliac trunk specific reference to hepatic artery pattern in the west-indian population. Indian J Surg. 2014; 76(5): 359-362, doi: 10.1007/s12262-012-0707-1, indexed in Pubmed: 26396468.

16. Song SY, Chung JW, Yin YHu, et al. Celiac axis and common hepatic artery variations in 5002 patients: systematic analysis with spiral CT and DSA. Radiology. 2010; 255(1): 278-288, doi: 10.1148/radiol.09090389, indexed in Pubmed: 20308464.

17. Standring S. Gray's Anatomy: The Anatomical Basis of Clinical Practice, 40th Ed. Churchill Livingstone, Edinburgh and London 2008.

18. Ugurel MS, Battal B, Bozlar U, et al. Anatomical variations of hepatic arterial system, coeliac trunk and renal arteries: an analysis with multidetector CT angiography. Br J Radiol. 2010; 83(992): 661-667, doi: 10.1259/bjr/21236482, indexed in Pubmed: 20551256.

19. Wadhwa A, Sonia SA. composite study of coeliac trunk in 30 adult human cadavers - its clinical implications. Glob J Med Res. 2011; 11(1): 35-38. 